\title{
HIV-1 Evolutionary Patterns Associated with Metastatic Kaposi's Sarcoma during AIDS
}

\author{
Susanna L. Lamers, ${ }^{1}$ Rebecca Rose, ${ }^{1}$ David J. Nolan, ${ }^{2}$ Gary B. Fogel, ${ }^{3}$ Andrew E. Barbier, ${ }^{1}$ \\ Marco Salemi, ${ }^{2}$ and Michael S. McGrath ${ }^{4}$ \\ ${ }^{1}$ Bioinfoexperts, LLC, 718 Bayou Lane, Thibodaux, LA 70302, USA \\ ${ }^{2}$ Department of Pathology and Laboratory Medicine, University of Florida, 2055 Mowry Road, Gainesville, FL 32610, USA \\ ${ }^{3}$ Natural Selection, Inc., 5910 Pacific Center Blvd., 6480 Weathers Place, San Diego, CA 92121, USA \\ ${ }^{4}$ The AIDS and Cancer Specimen Resource, University of California at San Francisco and the Department of Laboratory Medicine, \\ Pathology, and Medicine, University of California at San Francisco, 1001 Poterero Ave, Bldg 3, Rm 207, UCSF Box 1317, San Francisco, \\ CA 94110, USA
}

Correspondence should be addressed to Michael S. McGrath; mike.mcgrath@ucsf.edu

Received 11 May 2016; Accepted 7 August 2016

Academic Editor: C. Verhoef

Copyright ( 2016 Susanna L. Lamers et al. This is an open access article distributed under the Creative Commons Attribution License, which permits unrestricted use, distribution, and reproduction in any medium, provided the original work is properly cited.

\begin{abstract}
Kaposi's sarcoma (KS) in HIV-infected individuals can have a wide range of clinical outcomes, from indolent skin tumors to a life-threatening visceral cancer. KS tumors contain endothelial-related cells and inflammatory cells that may be HIV-infected. In this study we tested if HIV evolutionary patterns distinguish KS tumor relatedness and progression. Multisite autopsies from participants who died from HIV-AIDS with KS prior to the availability of antiretroviral therapy were identified at the AIDS and Cancer Specimen Resource (ACSR). Two patients (KS1 and KS2) died predominantly from non-KS-associated disease and KS3 died due to aggressive and metastatic KS within one month of diagnosis. Skin and visceral tumor and nontumor autopsy tissues were obtained $(n=12)$. Single genome sequencing was used to amplify HIV RNA and DNA, which was present in all tumors. Independent HIV tumor clades in phylogenies differentiated KS1 and KS2 from KS3, whose sequences were interrelated by both phylogeny and selection. HIV compartmentalization was confirmed in KS1 and KS2 tumors; however, in KS3, no compartmentalization was observed among sampled tissues. While the sample size is small, the HIV evolutionary patterns observed in all patients suggest an interplay between tumor cells and HIV-infected cells which provides a selective advantage and could promote KS progression.
\end{abstract}

\section{Introduction}

Prior to the human immunodeficiency virus (HIV) epidemic, Kaposi's sarcoma (KS) was considered a very rare disease, found primarily in Mediterranean countries and in organ transplant recipients [1]. Although Human Herpes Virus 8 (HHV8) is the etiological cause of KS [2], most $\mathrm{HHV}^{+}$ individuals do not develop KS. Early in the HIV epidemic, KS was so frequently diagnosed that it was considered an AIDSdefining illness [3-5]. Prior to the mid-1990s and the use of combined antiretroviral therapy (cART), $\mathrm{HIV}^{+}$patients had a $40 \%$ lifetime risk of developing KS [6]. Although combined antiretroviral therapy (cART) has undeniably reduced KSassociated mortality among HIV-infected patients [7-9], the statistical impact is unclear due to differing clinical definitions and cART adherence problems [10, 11]. Furthermore, KS is still one of the most common cancers among $\mathrm{HIV}^{+}$ patients [12] despite cART-improved $\mathrm{CD}^{+}{ }^{+} \mathrm{T}$-cell counts, low viral loads, and reduced risk of opportunistic infections [13-16]. KS is particularly problematic in resource-poor settings where cART and chemotherapy are limited [6, 1719]; however, even in resource-rich settings, full remission of KS using cART and chemotherapy occurs in less than $50 \%$ of $\mathrm{HIV}^{+}$patients with disseminated disease [20]. 
KS lesions can be solitary, localized, or disseminated, but the relationship among tumors in a single individual is largely unknown. While many KS lesions are cutaneous and indolent, tumors can occur in the oral cavity, lymph nodes, and viscera, which can result in fatal complications due to interference with normal body function. The growth of lesions can be very slow or explosively fast. The KS defining cell-type is a spindle cell (SC) [21, 22] that expresses markers of both endothelial and macrophage lineages [23]. KS tumors are polyclonal, positive for the presence of HHV8 virus, which infects the tumor-associated B-cells and SCs [23], and highly vascularized, giving them a distinguishing purple color. Inflammatory lymphocytes and monocytes/macrophages populate and enrich the KS tumor environment for tumor growth through production of a variety of cytokines [23]. These immune cells are all potential targets for HIV; however, to our knowledge, only one study assessed KS tumors for the presence of HIV using an early hybridization technique [24]. SCs can be cultured from PBMCs of patients with KS, suggesting that circulating SCs may lead to the appearance of multiple KS lesions [23].

HIV has the potential to infect and evolve in many anatomical tissues, including tumors [25-27]. Previously, we showed that the viral populations in lymphoma tumors were distinct from HIV in healthy tissues [25]. Here, our goal was to characterize HIV populations in KS tumors to determine whether HIV evolution could be used to track tumor relatedness and progression in native KS uncomplicated by the use of cART. We obtained tumor and nontumor tissues sampled post mortem from the AIDS and Cancer Specimen Resource (ACSR) from three $\mathrm{HIV}^{+} / \mathrm{KS}^{+}$patients who died from aggressive AIDS, and we generated HIV env-nef sequences using single genome sequencing (SGS) to characterize viral evolutionary patterns.

\section{Materials and Methods}

2.1. Patients and Biomaterial. The three male patients included in this study were diagnosed with HIV infection and died with advanced AIDS without receiving cART (Table 1). $100 \mathrm{mg}$ of frozen autopsy tumor and nontumor tissues was obtained through the ACSR (http://acsr.ucsf.edu/). Tissues were classified as tumor or nontumor by histological examination. The ACSR is a National Cancer Institute-funded tissue-banking program that obtains tissues from patients after appropriate consent and releases tissues to investigators following approval of the proposed study and deidentification of samples and clinical histories. The ACSR is recognized by the Office of Biorepositories and Biospecimen Research at the National Institutes of Health as being HIPAA compliant and in accordance with the ethical standards of the Declaration of Helsinki. Additionally, all material was obtained under approval from the University of California at San Francisco Committee on Human Research.

2.2. RNA/DNA Extractions. Total RNA and genomic DNA were isolated separately from each tissue section (30-50 ng) using AllPrep DNA/RNA Mini Kit (Qiagen \#80204). Tissues were homogenized just prior to extraction in Buffer RLT Plus (lysis buffer) using a TissueRupter rotor-stator homogenizer (Qiagen \#9001271) with a fresh sterile disposable probe (Qiagen \#990890) for each sample. Manufacturer's guidelines were followed, with the exception of two $50 \mu \mathrm{L}$ final elutions using RNase-free water during the RNA isolation. The $100 \mu \mathrm{L}$ final volume of RNA generated was concentrated using RNeasyMinElute Cleanup Kit (Qiagen \#74204). RNA and DNA extractions, cDNA synthesis, and first-round PCR setup were conducted in a restricted-access, amplicon-free room with separate air handling and laboratory equipment where no amplified PCR products or recombinant cloned plasmids were allowed, and work surfaces and equipment were thoroughly cleaned before and after use with Eliminase ${ }^{\circledR}$ (Decon Labs, Inc.). cDNA was synthesized using SuperScript ${ }^{\circledR}$ III First-Strand Synthesis System (Invitrogen Life Technologies \#18080-051) using the provided Oligo(dT) ${ }_{20}$ primer according to manufacturer's recommendations. RNA was incubated at $65^{\circ} \mathrm{C}$ for 5 minutes with deoxynucleoside triphosphates $(0.5 \mathrm{mM})$ and $5 \mu \mathrm{M}$ Oligo $(\mathrm{dT})_{20}$ and then cooled quickly to $4^{\circ} \mathrm{C}$. First-Strand cDNA Synthesis was performed in a $40 \mu \mathrm{L}$ reaction volume containing $1 \mathrm{x}$ reverse transcription buffer (10 mM Tris- $\mathrm{HCl}$ [pH 8.4], $25 \mathrm{mMKCl}$ ), $5 \mathrm{mM} \mathrm{MgCl}_{2}, 10 \mathrm{mM}$ dithiothreitol, $2 \mathrm{U} / \mu \mathrm{L}$ of RNase-OUT ${ }^{\mathrm{TM}}$ (RNase inhibitor), and $10 \mathrm{U} / \mu \mathrm{L}$ SuperScript III RT. The reaction was heated to $50^{\circ} \mathrm{C}$ for 50 minutes, followed by $85^{\circ} \mathrm{C}$ for 5 minutes. The reaction was cooled to $37^{\circ} \mathrm{C}$ and $0.1 \mathrm{U} / \mu \mathrm{L}$ of $E$. coli RNase $\mathrm{H}$ was added, followed by a $20-$ minute incubation. cDNA was stored at $-20^{\circ} \mathrm{C}$.

2.3. Sequencing Protocol. A modified single genome sequencing protocol was used to amplify linked HIV env and nef sequences [28]. cDNA and genomic DNA were serially diluted until an average of $30 \%$ or less of the nested PCR reactions were positive. During the first-round PCR, diluted cDNA or genomic DNA was amplified in $25 \mu \mathrm{L}$ reactions containing $1 \mathrm{x}$ Platinum ${ }^{\circledR}$ Blue PCR SuperMix (Invitrogen Life Technologies) and $0.2 \mu \mathrm{M}$ of each primer: EF2, $5^{\prime}$-ACAGTCTATTATGGGGTRCC-3' and NR1, $5^{\prime}$ AGCTCCCAGGCTCAGATCT-3' (6333-6352 bp and 95589576 bp of HIV HXB2, resp.) with the following cycling parameters: initial denaturation $95^{\circ} \mathrm{C}$ for 5 minutes, followed by 35 cycles of denaturing at $94^{\circ} \mathrm{C}$ for 1 minute, annealing at $58^{\circ} \mathrm{C}$ for 1 minute, and extension at $72^{\circ} \mathrm{C}$ for 4 minutes, with a final extension time of 10 minutes at $72^{\circ} \mathrm{C}$. A second round of gp120 PCR consisted of $1 \mu \mathrm{L}$ of the first-round PCR added to a $24 \mu \mathrm{L}$ second-round reaction consisting of $1 \mathrm{x}$ Platinum Blue PCR SuperMix (Invitrogen Life Technologies) and $0.2 \mu \mathrm{M}$ of each primer: EF3, $5^{\prime}$ CATAATGTTTGGGCCACACA$3^{\prime}$ and ER2, 5'-CACCACTCTTCTYTTTGCC-3' (6420$6439 \mathrm{bp}$ and $7724-7742 \mathrm{bp}$ of HIV HXB2, resp.) with the following cycling parameters: initial denaturation $95^{\circ} \mathrm{C}$ for 5 minutes, followed by 35 cycles of denaturation at $94^{\circ} \mathrm{C}$ for 1 minute, annealing at $58^{\circ} \mathrm{C}$ for 1 minute, and extension at $72^{\circ} \mathrm{C}$ for 2 minutes, with a final extension time of 10 minutes at $72^{\circ} \mathrm{C}$. This second-round PCR generated a $1.3 \mathrm{~Kb}$ product, nearly covering the entire env gp120 gene. Second-round env gp120 PCR products were visualized on 1\% agarose gels stained with ethidium bromide, and reactions containing a single $1.3 \mathrm{~Kb}$ product were considered positive and selected 


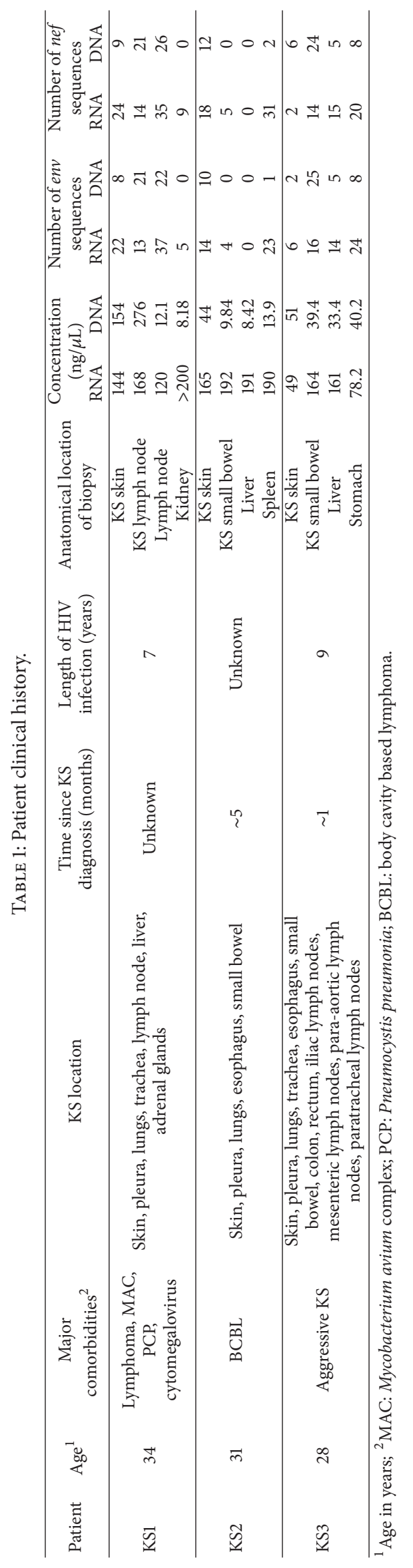


for sequencing. Subsequently, the first-round reactions that corresponded to positive second-round gp120 PCRs were then used to amplify the nef gene sequence. Second-round nef PCR consisted of $1 \mu \mathrm{L}$ of the first-round PCR added to a $24 \mu \mathrm{L}$ second-round reaction consisting of $1 \mathrm{x}$ Platinum Blue PCR SuperMix (Invitrogen Life Technologies) and $0.2 \mu \mathrm{M}$ of each primer: NF1, $5^{\prime}$-TTAGGCAGGGATAYTCACC-3' and NR2, $5^{\prime}$-ATCTGAGGGCTCGCCACT-3' (8347-8365 bp and 9488-9505 of HIV HXB2, resp.) with the following cycling parameters: initial denaturation $95^{\circ} \mathrm{C}$ for $5 \mathrm{~min}-$ utes, followed by 35 cycles of denaturation at $94^{\circ} \mathrm{C}$ for 1 minute, annealing at $58^{\circ} \mathrm{C}$ for 1 minute, and extension at $72^{\circ} \mathrm{C}$ for 2 minutes, with a final extension at $72^{\circ} \mathrm{C}$ for 10 minutes. Second-round nef PCRs were visualized on $1 \%$ agarose gels stained with ethidium bromide, and reactions containing single $1.1 \mathrm{~Kb}$ products were considered positive and selected for sequencing. The primers were designed using Primer3 (http://bioinfo.ut.ee/primer3-0.4.0/) and by observing regions of conservation in alignments of published HIV subtype B sequences downloaded from Los Alamos HIV Sequence Database (http://www.hiv.lanl.gov/). Sequencing was performed on an Applied Biosystems 3730xl DNA Analyzer (Life Technologies) at the University of Florida Interdisciplinary Center for Biotechnology Research (UF ICBR). All sequences were assembled and aligned with the Geneious R7 software package (Biomatters http://www.geneious.com/) followed by a manual optimization of regions containing insertions and deletions. Sequence data has been submitted to GenBank (Accession numbers KU709129-KU709831).

2.4. Sequence Analysis. Env and nef alignments were generated using ClustalW [29] in MEGA5 [30] with further optimization performed by hand. Due to a large number of insertions and deletions that are typically problematic to align, regions with substantial insertions and deletions in env V1, V2, and V4 domains were removed. An initial maximumlikelihood phylogeny was inferred using sequences from all patients for both genes to ensure no cross-contamination. Pairwise distance analysis within and between RNA and DNA tissue sequence populations over time was assessed in MEGA5 [30] using the Tamura-Nei molecular model (identified using Model-Selection) with standard error estimated by 1000 bootstrap replicates. The Kruskal-Wallis test was used to determine significance between the mean pairwise distances in different anatomical tissues. Individual maximumlikelihood phylogenies were inferred for each patient under a GTR model of nucleotide evolution and gamma distributed rate variation among sites $(+G)$ using PhyML [31]. Statistical support was assessed with 200 bootstrap replicates. The Slatkin-Maddison test [32] was used to determine compartmentalization between sequences derived from different tissues, and significance was assessed using 1,000 replicates of tip randomization, implemented in HYPHY v.1.0 [33]. The fast, unconstrained Bayesian approximations for inferring selection (FUBAR) model, implemented in Data Monkey (http://datamonkey.org/), were used to identify amino acid sites under selection in sequences derived from different tissues for each individual. Sites with posterior probability $>0.9$ of an increased (diversifying) or decreased (purifying) rate of nonsynonymous relative to synonymous substitutions were considered to have experienced a significant level of selective pressure. Selected sites were numbered according to the molecular HIV clone HXB2 (GenBank Accession \#AF358141).

\section{Results}

3.1. Clinical Characteristics of the Patient Cohort. All patients (KS1-KS3) had CD 4 counts $<50$ cells $/ \mathrm{mm}^{3}$ at death and were diagnosed with KS only months prior to death (Table 1). KS1 lived with HIV infection for seven years. He was hospitalized due to Mycobacterium avium complex, Pneumocystis pneumonia, and wasting syndrome eleven months prior to death. Five months prior to death, medical notes indicate multiple AIDS-like symptoms; however, KS was not specified. At autopsy, numerous infections were identified throughout his body, including disseminated KS, which either had not been previously reported or had originated closer to death. KS2's clinical history is similar to that of KS1 in having multiple infections; however, this patient had an initial KS diagnosis five months prior to death. Also, this patient was diagnosed with an aggressive body cavity based lymphoma (BCBL) four months prior to death that was treated with chemotherapy. BCBL may be related to primary effusion lymphoma which is typically caused by HHV8, the Kaposi sarcoma herpes virus. KS3 had a nine-year history of HIV infection with reoccurring upper respiratory tract infections. He was diagnosed with KS one month prior to death. His KS lesions became rapidly disseminated on the skin and internally, which lead directly to his death due to respiratory distress.

\subsection{HIV RNA and DNA Was Successfully Sequenced from} All KS Tumors. Viral sequences were obtained from RNA in 13/14 tissues and from DNA in 12/14 tissues (Table 1). A preliminary maximum-likelihood (ML) phylogenetic tree of all sequences confirmed a distinct population of HIV sequences for each patient, indicating no laboratory crosscontamination.

3.3. KS Tumors Can Contain Distinct HIV Isolates. ML phylogenies were inferred for env and nef sequence populations for all three patients. In the KS1 env phylogeny, four distinct and well-supported clades (A-D) were apparent that contained the majority of tumor-derived sequences (Figure 1). The relatively long internal branches leading to each clade indicate considerable divergence from the rest of the viral population. The majority of lymph node tumor sequences $(19 / 34)$ were within two distinct clades (A, D). The majority of skin tumor sequences (20/32) were also located in two different distinct clades (B-C). One of these (B) contained both DNA and RNA sequences, while the other (C) was comprised exclusively of RNA skin tumor sequences. Most of the terminal branches leading directly to skin tumorderived sequences were very short, while those leading to the lymph node tumor-derived sequences were considerably longer and showed more branching within the clade. The 

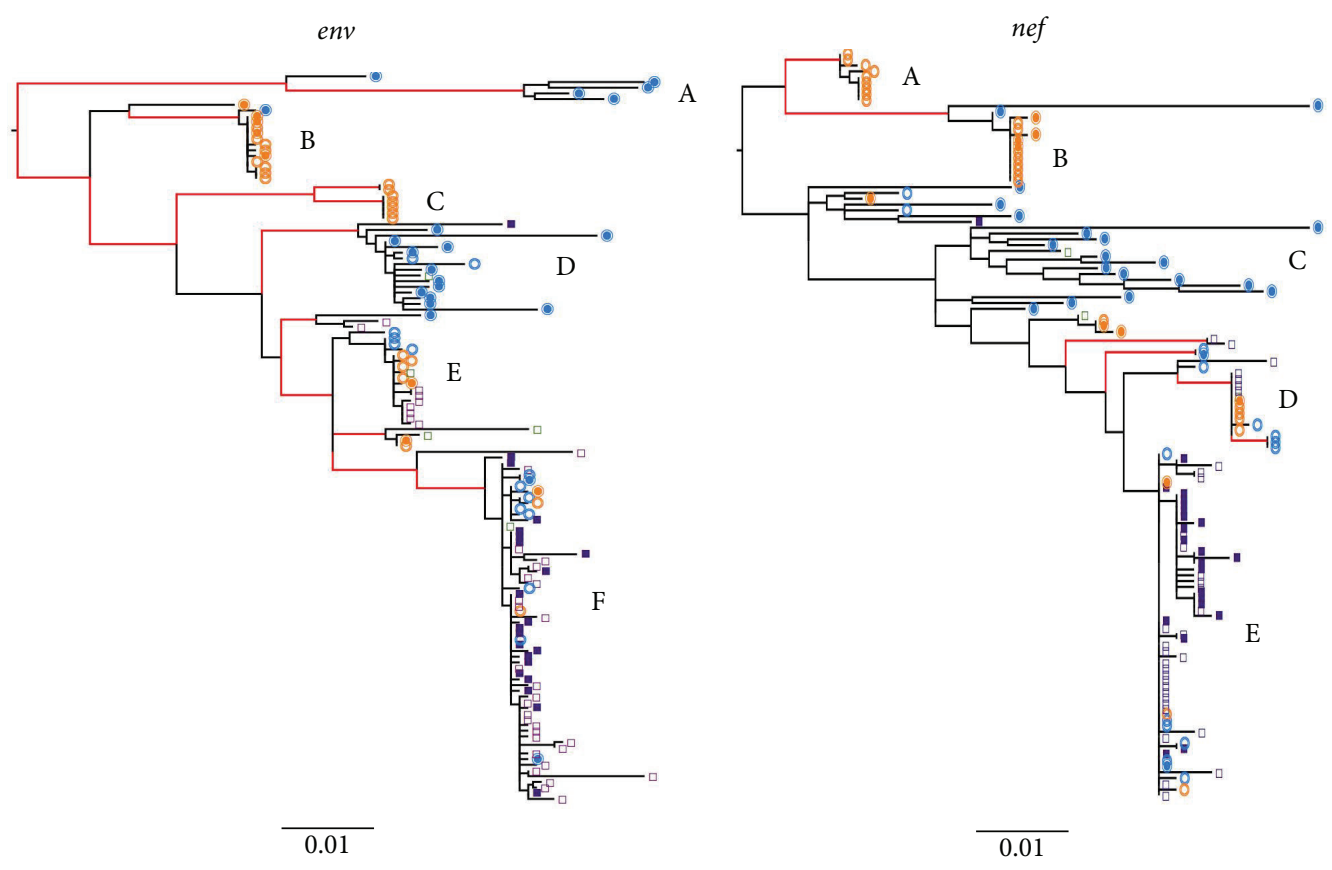

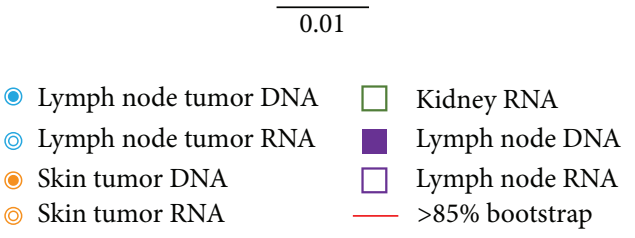

(a)

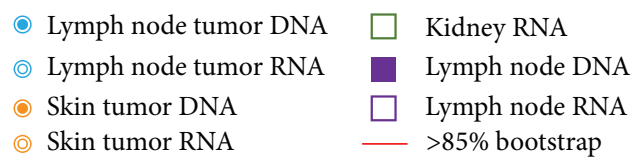

(b)

FIGURE 1: Maximum-likelihood phylogenies for KS1. Phylogenies were inferred for each patient using env (a) and nef (b) sequence alignments. Tips are labeled with symbols corresponding to the tissue of origin for each sequence. Branches with red lines indicate bootstrap values $>85 / 200$. Branches are scaled in substitutions/site according to the scale under each tree. Clades labeled A-F are discussed in the text.

remaining lymph node and skin tumor RNA and DNA sequences were located in highly mixed clades (E-F). The nef phylogeny for KS1 had similar branching patterns, with even more pronounced diversity in one lymph node tumor clade (C). Similarly, all skin tumor-derived sequences except one clustered together in a distinct and well-supported clade in KS2 for both env and nef (A) (Figure 2). Small bowel tumorderived RNA sequences were interspersed with the nontumor spleen-derived sequences in both genes; however, few bowelderived sequences were obtained $(n=9)$. Branches in the nontumor clade showed considerable structure in both genes, consistent with a continuously diversifying virus population. In the nef phylogeny, two distinct clades were evident within the mixed clade, which was not present in the env tree. In contrast, for KS3, all tumor- and nontumor-derived sequences were largely interspersed in both env and nef phylogenies (Figure 3). Three well-supported clades were present in both genes $(\mathrm{A}-\mathrm{C})$. Interestingly, this patient was diagnosed with advanced and aggressive tumorigenesis less than one month prior to death.

3.4. KS-Associated Virus Is Compartmentalized in Tumors in KS1 and KS2 but Not in KS3. When pairwise distances were calculated for sequences derived from each tumor and nontumor tissue, only one significant difference was observed $(p<0.001)$ (KS1 lymph node tumor nef versus nontumor nef sequences). Viral populations were significantly compartmentalized within each of the two tumors and normal tissues for both env and nef in KS1 and KS2 $(p<0.001)$. On the other hand, gene flow among the three sites was found in both genes in KS3 (env: $p=0.021$; nef: $p=0.171$ ). Viral populations from combined tumor locations were again significantly compartmentalized compared with nontumor populations in env and nef in $\mathrm{KS} 1$ and $\mathrm{KS} 2$, as well as in nef for KS3 $(p<0.001)$.

3.5. Positively and Negatively Selected Codons Were Fewer and Tissue-Specific in KS1 and KS2 in Contrast to KS3 (Tables 2 and 3). The proportion of codons under selection in env did not significantly vary between positively and negatively selected sites overall or within any single subject. However, the number of positions under either selective pressure was significantly higher in KS3 than in KS1 and KS2 $(p<0.01)$. In nef, a significantly higher number of negatively selected codons over positively selected codons were observed in all patients $(p<0.01)$. Codons under selection were tissuespecific in both KS1 and KS2, with only one being shared between two tissues in KS2. In contrast, in KS3 env sequence populations, all shared positively and negatively selected codons in tumor tissues were also identified within nontumor 

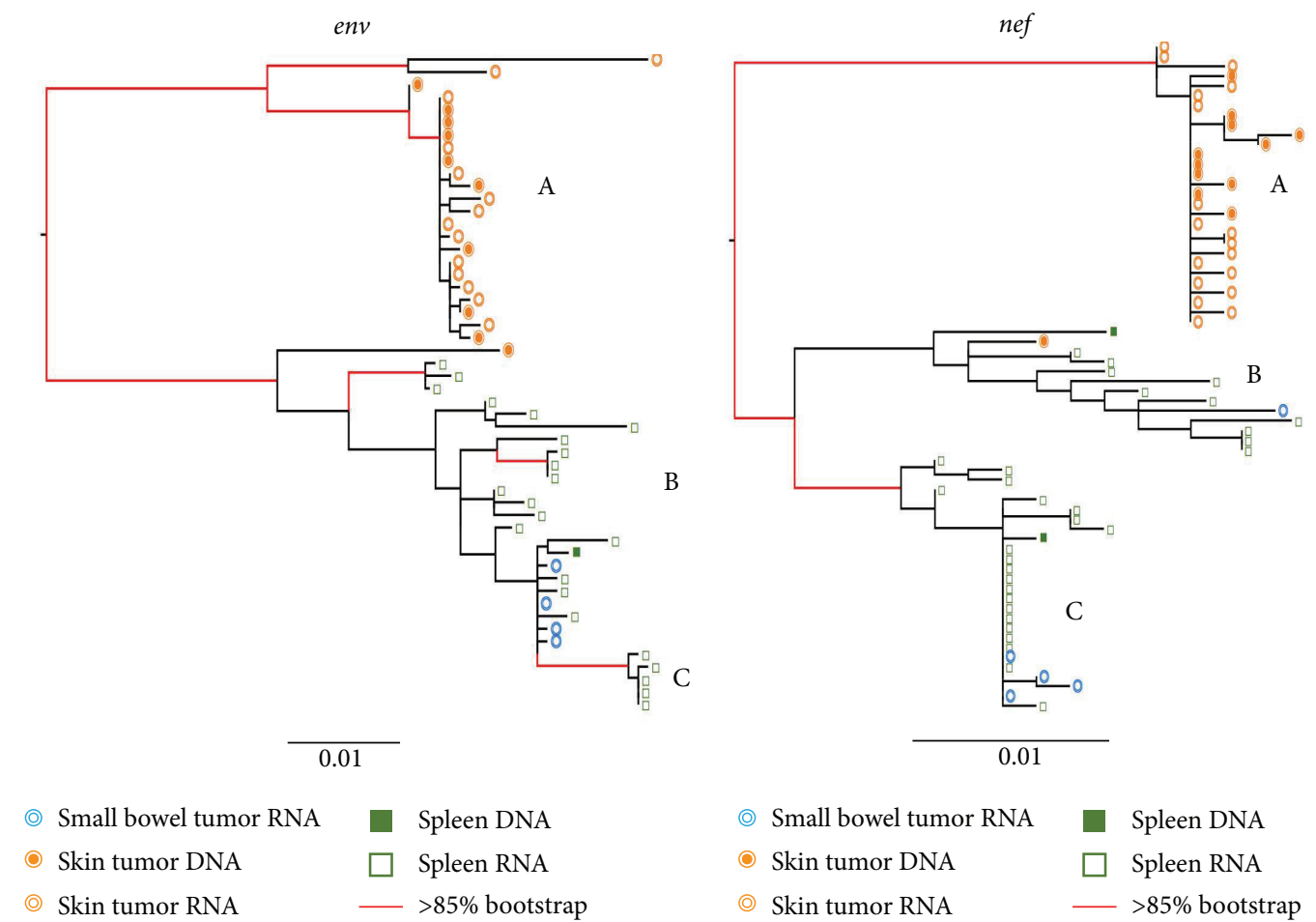

FIGURE 2: Maximum-likelihood phylogenies for KS2. See legend under Figure 1.
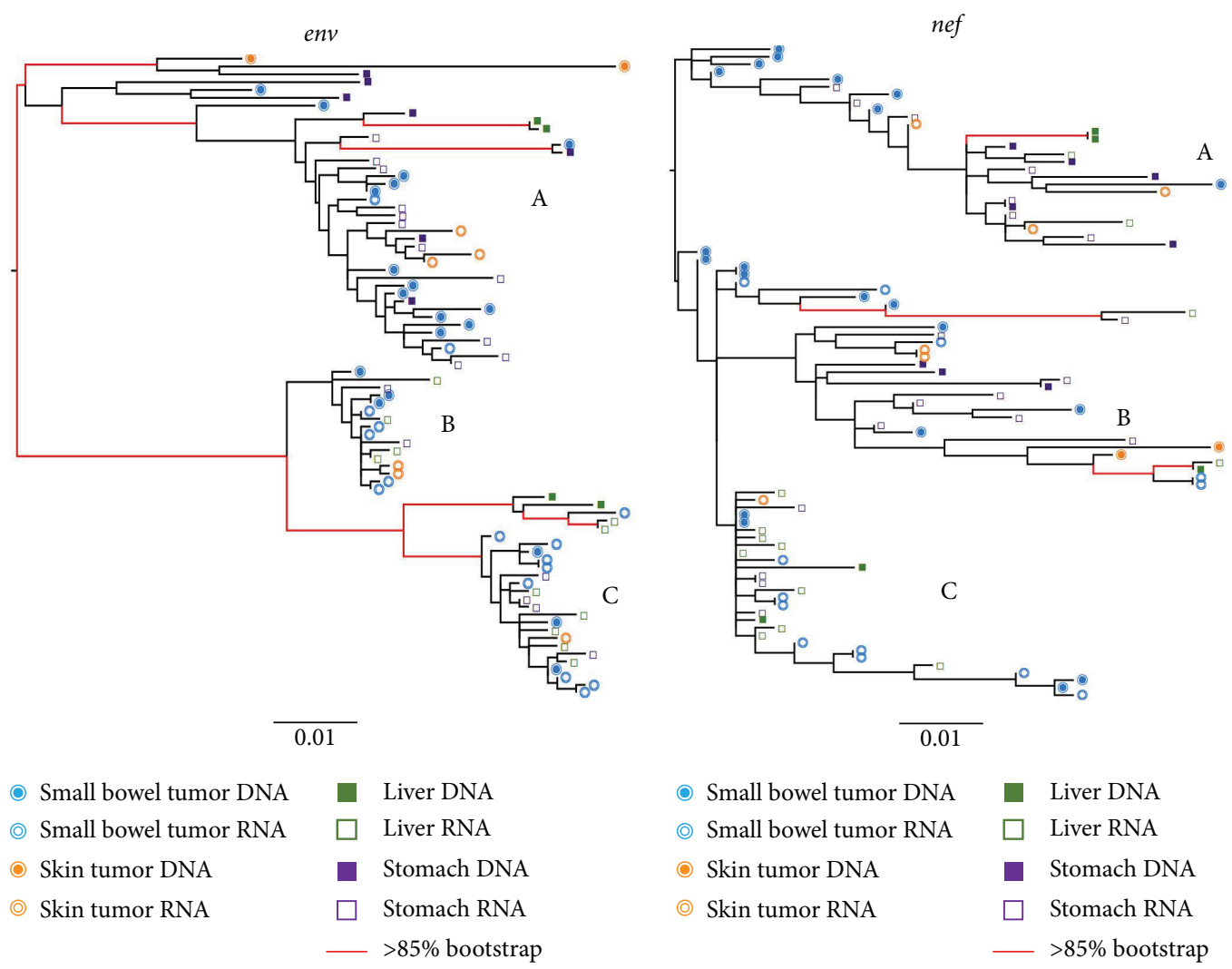

- Small bowel tumor DNA

( ) Small bowel tumor RNA

- Skin tumor DNA

Liver DNA

Liver RNA

( ) Skin tumor RNA

- Stomach DNA

$\square$ Stomach RNA

— > $>85 \%$ bootstrap

FIGURE 3: Maximum-likelihood phylogenies for KS3. See legend under Figure 1. 
TABLE 2: Number (and percent) of codons under positive or negative selection in tumor and nontumor sites in env sequence populations.

\begin{tabular}{|c|c|c|c|c|c|}
\hline Patient & Tissue & $\begin{array}{c}\text { \# positively } \\
\text { selected sites (\%) }\end{array}$ & $\begin{array}{l}\text { Codon position of shared } \\
\text { positively selected sites }\end{array}$ & $\begin{array}{l}\text { \# negatively } \\
\text { selected sites }\end{array}$ & $\begin{array}{l}\text { Codon position of shared } \\
\text { negatively selected sites }\end{array}$ \\
\hline \multirow{3}{*}{ KS1 (359) } & Skin tumor & $7(1.9)$ & None & $7(1.9)$ & na \\
\hline & $\begin{array}{l}\text { Lymph node } \\
\text { tumor }\end{array}$ & $1(0.3)$ & None & $7(1.9)$ & 122 \\
\hline & Nontumor & None & None & $8(2.2)$ & 122 \\
\hline \multirow{3}{*}{ KS2 (394) } & Skin tumor & $8(2.0)$ & 464 & $5(1.2)$ & 150 \\
\hline & $\begin{array}{l}\text { Small bowel } \\
\text { tumor }\end{array}$ & None & None & None & None \\
\hline & Nontumor & $5(1.2)$ & 373 & $4(1.0)$ & 150 \\
\hline \multirow{3}{*}{ KS3 (373) } & Skin tumor & $3(0.8)$ & 464 & $6(1.6)$ & 207,247 \\
\hline & $\begin{array}{l}\text { Small bowel } \\
\text { tumor }\end{array}$ & $10(2.6)$ & $183,336,396$ & $16(4.2)$ & $\begin{array}{l}103,118,207,228,238,246 \\
254,276,374,408,415,445\end{array}$ \\
\hline & Nontumor & $11(2.9)$ & $143,167,183,336,454$ & $21(5.6)$ & $\begin{array}{l}103,118,207,228,238,246 \\
254,276,374,408,415,445\end{array}$ \\
\hline
\end{tabular}

TABLE 3: Number (and percent) of codons under positive or negative selection in tumor and nontumor sites in nef sequence populations.

\begin{tabular}{|c|c|c|c|c|c|}
\hline Patient & Tissue & $\begin{array}{c}\text { \# positively } \\
\text { selected sites }\end{array}$ & $\begin{array}{l}\text { Codon position of shared } \\
\text { positively selected sites }\end{array}$ & $\begin{array}{l}\text { \# negatively } \\
\text { selected sites }\end{array}$ & $\begin{array}{l}\text { Codon position of shared } \\
\text { negatively selected sites }\end{array}$ \\
\hline \multirow{3}{*}{ KS1 (207) } & Skin tumor & 0 & None & $3(1.5)$ & 188 \\
\hline & $\begin{array}{l}\text { Lymph node } \\
\text { tumor }\end{array}$ & $4(1.9)$ & None & $18(8.7)$ & $8,37,188$ \\
\hline & Nontumor & $1(0.5)$ & None & $4(1.9)$ & $8,37,188$ \\
\hline \multirow{3}{*}{ KS2 (205) } & Skin tumor & $1(0.5)$ & 190 & 0 & None \\
\hline & $\begin{array}{l}\text { Small bowel } \\
\text { tumor }\end{array}$ & $1(0.5)$ & 190 & $4(2.0)$ & 81 \\
\hline & Nontumor & $2(1.0)$ & 190 & $5(2.4)$ & 81 \\
\hline \multirow{3}{*}{ KS3 (207) } & Skin tumor & $1(0.5)$ & None & $7(3.4)$ & $30,65,147,151,191,195$ \\
\hline & $\begin{array}{l}\text { Small bowel } \\
\text { tumor }\end{array}$ & $1(0.5)$ & None & $14(6.8)$ & $\begin{array}{c}4,30,63,65,111,129,151 \\
164,191,195\end{array}$ \\
\hline & Nontumor & $1(0.5)$ & None & $21(10.1)$ & $\begin{array}{c}4,63,111,129,147,151,164, \\
191,195\end{array}$ \\
\hline
\end{tabular}

sequences; similarly, in KS3 nef sequence populations, all shared selected codons from tumors were identified in nontumor tissues except codon positions 31 and 67.

\section{Discussion}

In this study we examined if HIV evolutionary patterns could differentiate metastatic KS in patients untreated with cART. We analyzed HIV env and nef sequences from tumor and nontumor anatomical sites from three subjects who died with KS. Medical records indicated that subjects KS1 and KS2 had a slower KS progression than subject KS3; however, all patients had visceral KS, indicating an advanced cancer at death from AIDS. HIV RNA and/or DNA was amplified from all tumors in the study, demonstrating that, similar to a previous study [25], cancer tissues contain substantial amounts of HIV. Furthermore, HIV sequence populations from most tissues had similar genetic distances, indicating no constraints to HIV evolution in any of the tissue environments examined.
HIV from tumor sites in KS1 and KS2 was compartmentalized relative to the nontumor virus, with limited gene flow between compartments; however, subpopulations of virus were also present within tumors. Additionally, codon selection analysis demonstrated that, at the protein level, KS1 and KS2 had sequence populations evolving under independent selective pressures in different tumor/nontumor sites. In contrast, the patient who died from highly aggressive KS (KS3) showed remarkably different patterns. Here the virus in tumor and nontumor tissue was completely interspersed with a non-tissue-specific viral population structure. These findings could result from a number of scenarios, including the following: (1) subpopulations of virus in tumor could result from recent viral migration from another, unsampled anatomical location; (2) the viral population in the tumors is evolving independently due to a physical barrier restricting gene flow; (3) the viral populations in the tumors are evolving in response to local selective pressures; (4) viral sequences in one or more sites could represent archival virus that was 
reactivated because of the cancer growth. The first scenario is untestable here; however, we are conducting additional studies with more tumor and nontumor tissues from other KS patients, including KS derived from patients on cART with no detectable plasma viral load. While the second scenario is possible, unlike the brain in which viral flow is impeded by the blood-brain barrier, KS tumors are highly vascularized which would in theory provide ample opportunity for migration. Furthermore, a small number of tumor viruses were found in nontumor tissues, also suggesting a lack of physical barrier. In considering the third and fourth scenario, we did find that codon positions were under varied selective pressures in the tumors from KS1 and KS2 when compared to nontumor tissues (as expected from the phylogeny). For KS3, most, but not all, selected codons were shared among tissues; however, this patient had widely metastatic KS at the time of death. Therefore, it is possible that tumor-compartmentalized HIV populations could have existed in this patient prior to the rapid outgrowth and spread of the cancer, perhaps represented by one of the distinct subpopulations.

Reactivation and clonal expansion of viral populations could be consistent with the large clades of identical or nearly identical tumor-associated virus in KS1 and KS2 phylogenies and with the separation of DNA and RNA derived sequences into different clades within tumors of KS1. This hypothesis could be investigated further by identifying the infected cells types within each tumor. Furthermore, identifying the insertion sites within the host genome in these tumors could help understand if HIV-infected cells in tumors are physically migrating to other tumor sites. A recent HIV integration site study showed that one mechanism of HIV persistence within T-cells is related to clonal expansion [34]. Interestingly, the authors also found that insertion sites were enriched for genes involved in cell growth [34], suggesting that the insertion sites themselves may promote tumorigenesis. Studies within cancer and AIDS dementia tissue macrophages performed in our lab showed that major HIV integration sites in tissueassociated macrophages (TAMs) were related to cellular activation including those just upstream of the $c$-fes oncogene, which could contribute to clonal expansion [35-38]. This is consistent with a sequential pathogenesis model in which the insertion site of the virus promotes persistent cellular activation, clonal expansion, and migration of $\mathrm{HIV}^{+}$from the tumor to nontumor sites [36].

The patients studied here were all cART-naïve; however, KS remains a substantial comorbidity even for patients undergoing CART. For some patients, rapid progression of KS occurs under cART even with an undetectable viral load [39]. These cases are frequently classified as related to immune reconstitution inflammatory syndrome (IRIS) [19, 39, 40], a well-studied phenomenon of resurgence of underlying pathologies during cART [41-46]. IRIS-related worsening of coinfections typically occurs within the first 6 months of therapy, is associated with localized tissue inflammation and low CD4 counts, and is most often observed in limitedresource settings [41, 47]. Although T-cell restoration and activation have been suggested as causing KS progression in these patients, no direct link has been demonstrated [47]. Innate immune dysfunction (e.g., macrophage-activation) has also been offered as an explanation for progressive KS during cART, whereby the interaction of restored T-cell populations with existing activated macrophages leads to increased IRIS [19].

\section{Conclusions}

Kaposi's sarcoma (KS) is a major cancer that still occurs in HIV positive patients despite immune-restorative combined antiretroviral therapy (cART). In this study we isolated HIV from tumor and nontumor tissue sites from patients who died with KS which had metastasized to the viscera (KS1-KS3). KS1 and KS2 died from other AIDS-associated complications, whereas KS3 died directly due to a highly aggressive KS that metastasized to lungs and caused death within 1 month of initial KS diagnosis. We compared the HIV sequences among patient's tissue sites and found that KS1 and KS2 had unique $\mathrm{HIV}$ in tumors compared to nontumor sites, whereas HIV was freely migrating among all tissues in KS3. While the study is based on a very small sample size, the results suggest that an HIV-associated mechanism may promote the metastatic process in aggressive KS. It is also important to note that it is unclear how the other AIDS-associated cancers may have impacted the study (e.g., lymphoma in KS1 and BCBL in KS2). Continued studies of the evolutionary patterns within and among KS tumors could help in understanding the mechanisms of metastasis as well as describing an additional HIV reservoir during cART. Evolutionary studies of HIV in tumor tissues are sorely lacking, and further investigation could provide additional clarity into the mechanisms of HIVassociated cancers.

\section{Disclosure}

The funders had no role in study design, data collection and interpretation, or the decision to submit the work for publication.

\section{Competing Interests}

The authors declare that they have no competing interests.

\section{Authors' Contributions}

Susanna L. Lamers and Rebecca Rose contributed equally to this work.

\section{Acknowledgments}

This work was supported by the U.S. National Institutes of Health under Grants NIMH R01-MH100984 and NCI ACSR UM1-CA181255-03 to Michael S. McGrath and Grants P50GM103297 and R01-NS063897 to Marco Salemi. Additional support was provided by Navidea Biopharmaceuticals, Inc.

\section{References}

[1] P. Cook-Mozaffari, R. Newton, V. Beral, and D. P. Burkitt, "The geographical distribution of Kaposi's sarcoma and of 
lymphomas in Africa before the AIDS epidemic," British Journal of Cancer, vol. 78, no. 11, pp. 1521-1528, 1998.

[2] Y. Chang, E. Cesarman, M. S. Pessin et al., "Identification of herpesvirus-like DNA sequences in AIDS-associated Kaposi's sarcoma," Science, vol. 266, no. 5192, pp. 1865-1869, 1994.

[3] http://www.cdc.gov/mmwr/preview/mmwrhtml/rr5710a2.htm.

[4] A. Stewart, S. Chan Carusone, K. To, N. Schaefer-Mcdaniel, M. Halman, and R. Grimes, "Causes of death in HIV patients and the evolution of an AIDS hospice: 1988-2008," AIDS Research and Treatment, vol. 2012, Article ID 390406, 7 pages, 2012.

[5] R. Rothenberg, M. Woelfel, R. Stoneburner, J. Milberg, R. Parker, and B. Truman, "Survival with the acquired immunodeficiency syndrome. Experience with 5833 cases in New York City," The New England Journal of Medicine, vol. 317, no. 21, pp. 1297-1302, 1987.

[6] J. H. Campbell, A. C. Hearps, G. E. Martin, K. C. Williams, and S. M. Crowe, "The importance of monocytes and macrophages in HIV pathogenesis, treatment, and cure," AIDS, vol. 28, no. 15, pp. 2175-2187, 2014.

[7] M. A. Eltom, A. Jemal, S. M. Mbulaiteye, S. S. Devesa, and R. J. Biggar, "Trends in Kaposi's sarcoma and non-Hodgkin's lymphoma incidence in the United States from 1973 through 1998," Journal of the National Cancer Institute, vol. 94, no. 16, pp. 1204-1210, 2002.

[8] A. M. Cattelan, M. L. Calabrò, P. Gasperini et al., "Acquired immunodeficiency syndrome-related Kaposi's sarcoma regression after highly active antiretroviral therapy: biologic correlates of clinical outcome," Journal of the National Cancer Institute. Monographs, no. 28, pp. 44-49, 2001.

[9] G. Di Lorenzo, P. A. Konstantinopoulos, L. Pantanowitz, R. Di Trolio, S. De Placido, and B. J. Dezube, "Management of AIDSrelated Kaposi's sarcoma," The Lancet Oncology, vol. 8, no. 2, pp. 167-176, 2007.

[10] A. S. Semeere, N. Busakhala, and J. N. Martin, "Impact of antiretroviral therapy on the incidence of Kaposi's sarcoma in resource-rich and resource-limited settings," Current Opinion in Oncology, vol. 24, no. 5, pp. 522-530, 2012.

[11] S. E. Krown, "Highly active antiretroviral therapy in AIDSassociated Kaposi's sarcoma: implications for the design of therapeutic trials in patients with advanced, symptomatic Kaposi's sarcoma," Journal of Clinical Oncology, vol. 22, no. 3, pp. 399402, 2004.

[12] E. L. Yanik, K. Tamburro, J. J. Eron, B. Damania, S. Napravnik, and D. P. Dittmer, "Recent cancer incidence trends in an observational clinical cohort of HIV-infected patients in the US, 2000 to 2011," Infectious Agents and Cancer, vol. 8, no. 1, article no. 18, 2013.

[13] D. Serraino, A. De Paoli, A. Zucchetto et al., "The impact of Kaposi sarcoma and non-Hodgkin lymphoma on mortality of people with AIDS in the highly active antiretroviral therapies era," Cancer Epidemiology, vol. 34, no. 3, pp. 257-261, 2010.

[14] L. Martín-Carbonero, R. Palacios, E. Valencia et al., "Long-term prognosis of HIV-infected patients with Kaposi sarcoma treated with pegylated liposomal doxorubicin," Clinical Infectious Diseases, vol. 47, no. 3, pp. 410-417, 2008.

[15] M. Bower, J. Weir, N. Francis et al., "The effect of HAART in 254 consecutive patients with AIDS-related Kaposi's sarcoma," AIDS, vol. 23, no. 13, pp. 1701-1706, 2009.

[16] S. E. Krown, J. Y. Lee, and D. P. Dittmer, "More on HIVassociated Kaposi's sarcoma," The New England Journal of Medicine, vol. 358, no. 5, pp. 535-536, 2008.
[17] A. Jemal, F. Bray, M. M. Center, J. Ferlay, E. Ward, and D. Forman, "Global cancer statistics," CA-A Cancer Journal for Clinicians, vol. 61, no. 2, pp. 69-90, 2011.

[18] E. A. Mesri, E. Cesarman, and C. Boshoff, "Kaposi's sarcoma and its associated herpesvirus," Nature Reviews Cancer, vol. 10, no. 10, pp. 707-719, 2010.

[19] E. Letang, J. J. Lewis, M. Bower et al., "Immune reconstitution inflammatory syndrome associated with Kaposi sarcoma: higher incidence and mortality in Africa than in the UK," AIDS, vol. 27, no. 10, pp. 1603-1613, 2013.

[20] H. Q. Nguyen, A. S. Magaret, M. M. Kitahata, S. E. Van Rompaey, A. Wald, and C. Casper, "Persistent Kaposi sarcoma in the era of highly active antiretroviral therapy: characterizing the predictors of clinical response," AIDS, vol. 22, no. 8, pp. 937945, 2008.

[21] S. Uccini, S. Scarpino, F. Ballarini et al., "In situ study of chemokine and chemokine-receptor expression in Kaposi sarcoma," The American Journal of Dermatopathology, vol. 25, no. 5, pp. 377-383, 2003.

[22] N. Dupin and P. A. Grange, "Looking for the target cell of Kaposi's sarcoma-associated herpesvirus," The Journal of Investigative Dermatology, vol. 126, no. 3, pp. 545-547, 2006.

[23] B. Ensoli, C. Sgadari, G. Barillari, M. C. Sirianni, M. Stürzl, and P. Monini, "Biology of Kaposi's sarcoma," European Journal of Cancer, vol. 37, no. 10, pp. 1251-1269, 2001.

[24] P. Delli Bovi, E. Donti, D. M. Knowles II et al., "Presence of chromosomal abnormalities and lack of AIDS retrovirus DNA sequences in AIDS-associated Kaposi's sarcoma," Cancer Research, vol. 46, no. 12, part 1, pp. 6333-6338, 1986.

[25] M. Salemi, S. L. Lamers, L. C. Huysentruyt et al., "Distinct patterns of HIV-1 evolution within metastatic tissues in patients with non-hodgkins Lymphoma," PLoS ONE, vol. 4, no. 12, Article ID e8153, 2009.

[26] S. L. Lamers, M. Salemi, D. C. Galligan et al., "Human immunodeficiency virus-1 evolutionary patterns associated with pathogenic processes in the brain," Journal of NeuroVirology, vol. 16, no. 3, pp. 230-241, 2010.

[27] S. L. Lamers, M. Salemi, D. C. Galligan et al., "Extensive HIV-1 intra-host recombination is common in tissues with abnormal histopathology," PLoS ONE, vol. 4, no. 3, Article ID e5065, 2009.

[28] S. Palmer, M. Kearney, F. Maldarelli et al., "Multiple, linked human immunodeficiency virus type 1 drug resistance mutations in treatment-experienced patients are missed by standard genotype analysis," Journal of Clinical Microbiology, vol. 43, no. 1, pp. 406-413, 2005.

[29] J. D. Thompson, T. J. Gibson, F. Plewniak, F. Jeanmougin, and D. G. Higgins, "The CLUSTAL $\mathrm{X}$ windows interface: flexible strategies for multiple sequence alignment aided by quality analysis tools," Nucleic Acids Research, vol. 25, no. 24, pp. 48764882, 1997.

[30] K. Tamura, D. Peterson, N. Peterson, G. Stecher, M. Nei, and S. Kumar, "MEGA5: molecular evolutionary genetics analysis using maximum likelihood, evolutionary distance, and maximum parsimony methods," Molecular Biology and Evolution, vol. 28, no. 10, pp. 2731-2739, 2011.

[31] S. Guindon, F. Delsuc, J.-F. Dufayard, and O. Gascuel, "Estimating maximum likelihood phylogenies with PhyML," Methods in Molecular Biology, vol. 537, pp. 113-137, 2009.

[32] M. Slatkin and W. P. Maddison, "A cladistic measure of gene flow inferred from the phylogenies of alleles," Genetics, vol. 123, no. 3, pp. 603-613, 1989. 
[33] D. W. Huang, B. T. Sherman, and R. A. Lempicki, "Bioinformatics enrichment tools: paths toward the comprehensive functional analysis of large gene lists," Nucleic Acids Research, vol. 37, no. 1, pp. 1-13, 2009.

[34] F. Maldarelli, X. Wu, L. Su et al., "Specific HIV integration sites are linked to clonal expansion and persistence of infected cells," Science, vol. 345, no. 6193, pp. 179-183, 2014.

[35] B. Shiramizu, B. Herndier, H. Abby, and M. S. McGrath, "Clonal HIV is present in a wide variety of HIV-associated malignancies and cell separation studies map the clone to tumor-associated macrophages," Journal of Acquired Immune Deficiency Syndromes \& Human Retrovirology, vol. 14, no. 4, article A50, 1997.

[36] M. S. McGrath, B. T. Shiramizu, and B. G. Herndier, "Identification of a clonal form of HIV in early Kaposi's sarcoma: evidence for a novel model of ontogenesis, 'sequential neoplasia," Journal of Acquired Immune Deficiency Syndromes and Human Retrovirology, vol. 8, no. 4, pp. 379-385, 1995.

[37] B. Shiramizu, B. G. Herndier, and M. S. McGrath, "Identification of a common clonal human immunodeficiency virus integration site in human immunodeficiency virus-associated lymphomas," Cancer Research, vol. 54, no. 8, pp. 2069-2072, 1994.

[38] K. D. Mack, X. Jin, S. Yu et al., "HIV insertions within and proximal to host cell genes are a common finding in tissues containing high levels of HIV DNA and macrophage-associated p24 antigen expression," Journal of Acquired Immune Deficiency Syndromes, vol. 33, no. 3, pp. 308-320, 2003.

[39] R. S. Leidner and D. M. Aboulafia, "Recrudescent Kaposi's sarcoma after initiation of HAART: a manifestation of immune reconstitution syndrome," AIDS Patient Care and STDs, vol. 19, no. 10, pp. 635-644, 2005.

[40] E. Letang, J. M. Almeida, J. M. Miró et al., "Predictors of immune reconstitution inflammatory syndrome-associated with kaposi sarcoma in mozambique: a prospective study," Journal of Acquired Immune Deficiency Syndromes, vol. 53, no. 5, pp. 589-597, 2010.

[41] M. Müller, S. Wandel, R. Colebunders, S. Attia, H. Furrer, and M. Egger, "Immune reconstitution inflammatory syndrome in patients starting antiretroviral therapy for HIV infection: a systematic review and meta-analysis," The Lancet Infectious Diseases, vol. 10, no. 4, pp. 251-261, 2010.

[42] S. A. Shelburne and R. J. Hamill, "The immune reconstitution inflammatory syndrome," AIDS Reviews, vol. 5, no. 2, pp. 67-79, 2003.

[43] S. A. Shelburne III, R. J. Hamill, M. C. Rodriguez-Barradas et al., "Immune reconstitution inflammatory syndrome: emergence of a unique syndrome during highly active antiretroviral therapy," Medicine, vol. 81, no. 3, pp. 213-227, 2002.

[44] M. A. French, P. Price, and S. F. Stone, "Immune restoration disease after antiretroviral therapy," AIDS, vol. 18, no. 12, pp. 1615-1627, 2004.

[45] S. F. Stone, P. Price, and M. A. French, "Immune restoration disease: a consequence of dysregulated immune responses after HAART,' Current HIV Research, vol. 2, no. 3, pp. 235-242, 2004.

[46] P. Price, N. Mathiot, R. Krueger, S. Stone, N. M. Keane, and M. A. French, "Immune dysfunction and immune restoration disease in HIV patients given highly active antiretroviral therapy," Journal of Clinical Virology, vol. 22, no. 3, pp. 279-287, 2001.

[47] N. F. Walker, N. F. Walker, N. F. Walker et al., "Immune reconstitution inflammatory syndrome in HIV-infected patients," HIV/AIDS - Research and Palliative Care, vol. 7, pp. 49-64, 2015. 


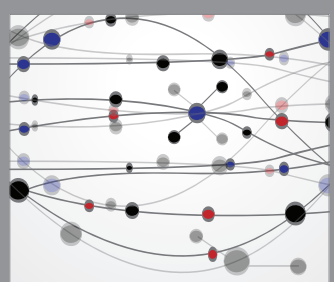

The Scientific World Journal
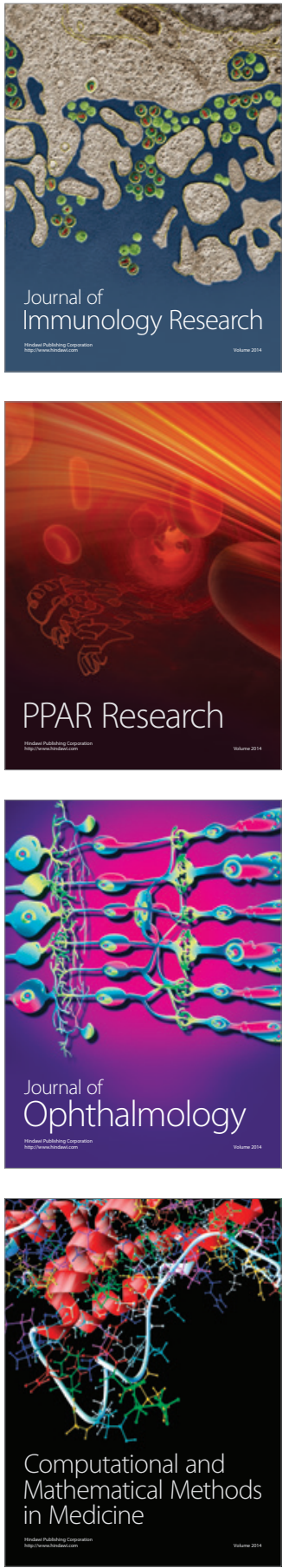

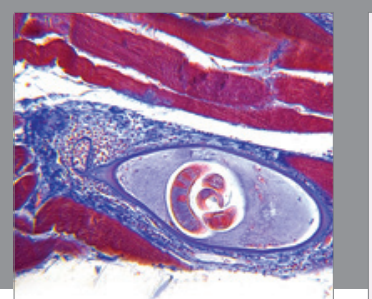

Gastroenterology Research and Practice

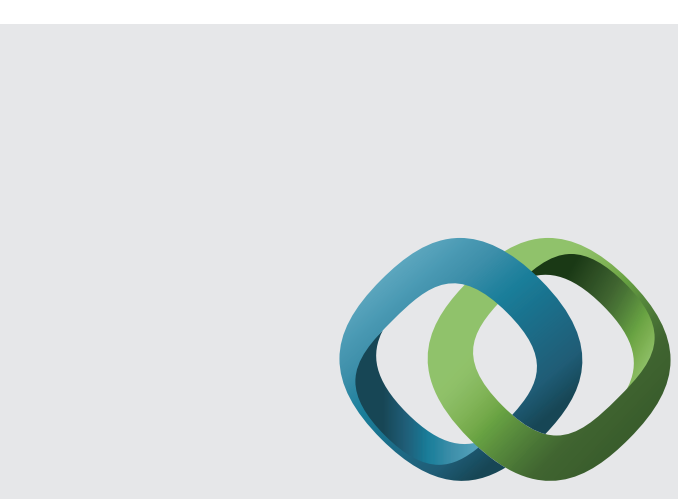

\section{Hindawi}

Submit your manuscripts at

http://www.hindawi.com
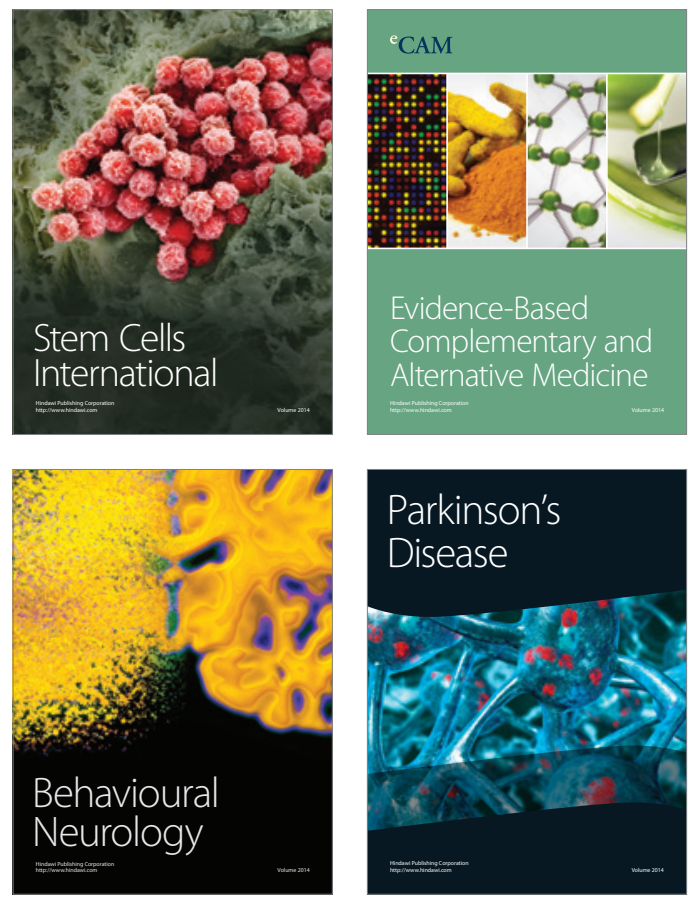
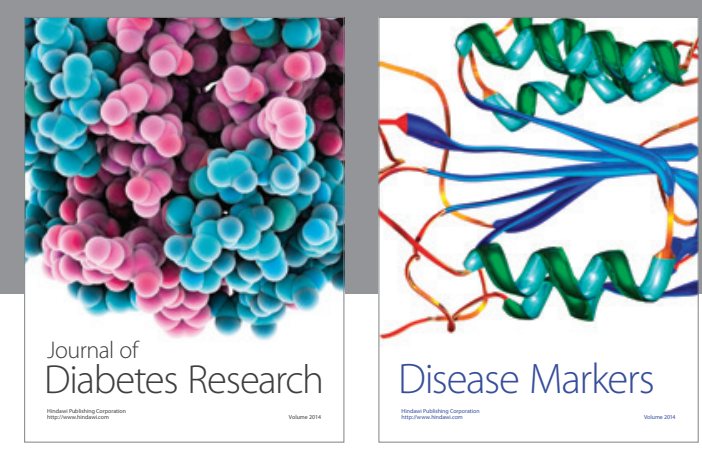

Disease Markers
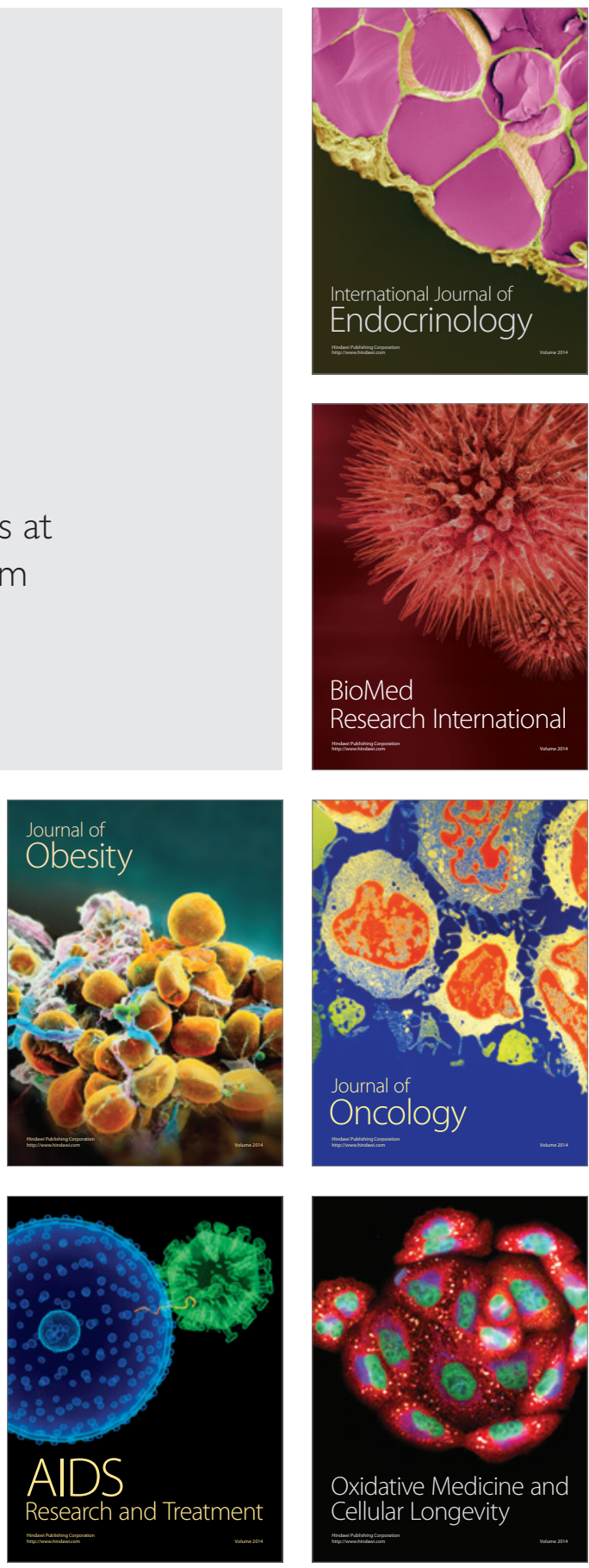